\title{
Standardized Water Budget Index and Validation in Drought Estimation of Haihe River Basin, North China
}

\author{
Shaohua Liu, ${ }^{1,2}$ Denghua Yan, ${ }^{1,2}$ Hao Wang, ${ }^{1,2}$ Chuanzhe Li, ${ }^{1,2}$ \\ Baisha Weng, ${ }^{1,2}$ and Tianling Qin ${ }^{1,2}$ \\ ${ }^{1}$ State Key Laboratory of Simulation and Regulation of Water Cycle in River Basin, China Institute of Water Resources and \\ Hydropower Research (IWHR), Beijing 100038, China \\ ${ }^{2}$ Water Resources Department, China Institute of Water Resources and Hydropower Research (IWHR), Beijing 100038, China \\ Correspondence should be addressed to Denghua Yan; yandh@iwhr.com
}

Received 23 February 2016; Revised 18 May 2016; Accepted 5 June 2016

Academic Editor: James Cleverly

Copyright (C) 2016 Shaohua Liu et al. This is an open access article distributed under the Creative Commons Attribution License, which permits unrestricted use, distribution, and reproduction in any medium, provided the original work is properly cited.

\begin{abstract}
The physical-based drought indices such as the self-calibrated Palmer Drought Severity Index (sc-PDSI) with the fixed time scale is inadequate for the multiscalar drought assessment, and the multiscalar drought indices including Standardized Precipitation Index (SPI), Reconnaissance Drought Index (RDI), and Standardized Precipitation Evapotranspiration Index (SPEI) based on the meteorological factors are lack of physical mechanism and cannot depict the actual water budget. To fill this gap, the Standardized Water Budget Index (SWBI) is constructed based on the difference between areal precipitation and actual evapotranspiration (AET), which can describe the actual water budget but also assess the drought at multiple time scales. Then, sc-PDSI was taken as the reference drought index to compare with multiscalar drought indices at different time scale in Haihe River basin. The result shows that SWBI correlates better with sc-PDSI and the RMSE of SWBI is less than other multiscalar drought indices. In addition, all of drought indices show a decreasing trend in Haihe River Basin, possibly due to the decreasing precipitation from 1961 to 2010 . The decreasing trends of SWBI were significant and consistent at all the time scales, while the decreasing trends of other multiscalar drought indices are insignificant at time scale less than 3 months.
\end{abstract}

\section{Introduction}

Drought is a complex and prolonged natural hazard affecting hydrological cycle, agriculture, environment, and economic development strongly [1-3]. Droughts have occurred over most parts of world, in both humid and arid region [4]. Therefore, much effort has been devoted to drought analysis, particularly in drought index, which is necessary to drought monitor, prediction, and management.

Many drought indices have been constructed in the last half century $[3,5,6]$. The Palmer Drought Severity Index (PDSI) [7] and the Standardized Precipitation Index (SPI) [8] are applied broadly. PDSI derived from a simple water balance model can identify the supply-demand dynamics and measure both drought and wet condition [9]. However, the PDSI values are not comparable between diverse climate regions. Therefore, in order to improve the spatial comparability of PDSI, Wells et al. [10] developed the selfcalibrated Palmer Drought Severity Index (sc-PDSI), which can demonstrate the severity of droughts across different climate regions and has become a standard for drought assessment [10]. Yet sc-PDSI is a fixed time scale drought index and drought is a multiscalar phenomenon [1]; thus drought indices should be related to a specific time scale for monitoring and assessing different droughts. For this reason, although SPI is merely dependent on precipitation, SPI has been widely used due to the less input, easy calculation, and multiscalar character. Furthermore, in order to take the other climate factors into consideration, the potential evapotranspiration (PET) was added into SPI. Subsequently, the Reconnaissance Drought Index (RDI) [11, 12] and the Standardized Precipitation Evapotranspiration Index (SPEI) [1] were developed and widely used in different climate regions of the world. Nevertheless, the RDI is inadequate 
in cold regions, where the potential evapotranspiration is approximately equal to 0 [13]. On the other hand, although the difference between precipitation and PET can represent the drought/wet condition to some extent, the deviation between PET and actual evapotranspiration (AET) makes the SPEI be insufficient to depict the actual regional water budget and results in an uncertain influence on drought assessment $[13,14]$.

Although these drought indices (sc-PDSI, SPI, RDI, and SPEI) have been popularly used for drought assessment over the world, there are some limitations to their applications. (1) The physical-based drought indices such as sc-PDSI can accurately represent the water budget, yet the fixed time scale of sc-PDSI is inadequate for the multiscalar drought assessment. (2) The multiscalar drought indices (SPI, RDI, and SPEI) based on the meteorological factors are lack of physical mechanism and cannot depict the actual water budget. Therefore, it is necessary to construct a Standardized Water Budget Index (SWBI), which can describe the actual water budget between AET and precipitation but also assess the drought at multiple time scales.

Haihe River basin is a drought-prone region with several prolonged drought events [2] and the drought here has become an obstacle to the development of socioeconomic system, environment system, and ecosystem [15]. The objectives of this paper are to (1) construct SWBI based on the actual water budget between AET and precipitation and (2) validate SWBI in comparison with other multiscalar drought indices and sc-PDSI in Haihe River basin. The remaining parts of the study are as follows: basic information of Haihe River basin is introduced firstly. Next, data sources and methods are illustrated in Section 3. Section 4 displays the calculation procedure of SWBI. Then the results and discussion are given out in Section 5. Finally, the conclusions are briefly presented in Section 6.

\section{Study Area}

According to the typical monsoon climate and diverse underlying surface system, China is a drought-prone country in the past half century, particularly in North China Plain [14, 16]. Haihe River basin located in the North of China consists of Luanhe watershed, Haihe watershed, and Tuhai-Majia River watershed (Figure 1). It is surrounded by Taihang Mountain in the west, Bohai Sea in the east, Mongolian Plateau in the north, and Yellow River in the south, and the area of basin is about $3.2 \times 10^{5} \mathrm{~km}^{2}$. Haihe River basin extends from semiarid region in the north to semihumid region in the south with the average annual areal precipitation of $530 \mathrm{~mm}$ and potential evapotranspiration of $960 \mathrm{~mm}$ during 19612010. The monthly distribution of precipitation and PET are shown in Figure 2, which illustrates that the monthly precipitation distribution is uneven and more than $70 \%$ of annual precipitation is concentrated in July to September, which makes the Haihe River basin a drought-prone region.

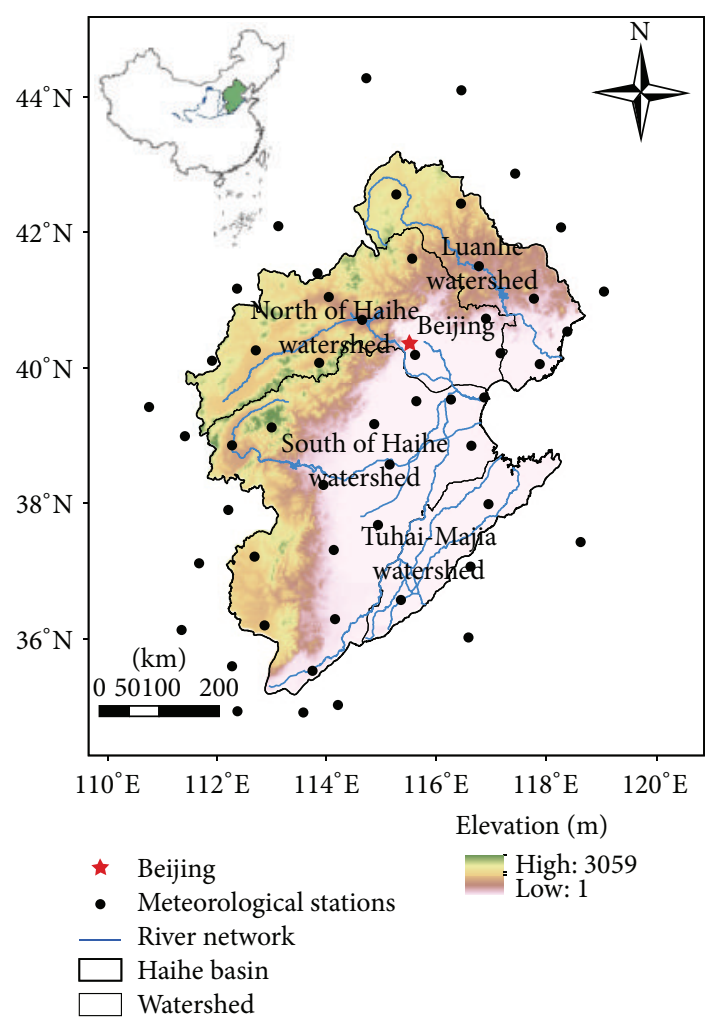

FIgURE 1: Topographic distribution of Haihe River basin and location of meteorological stations.

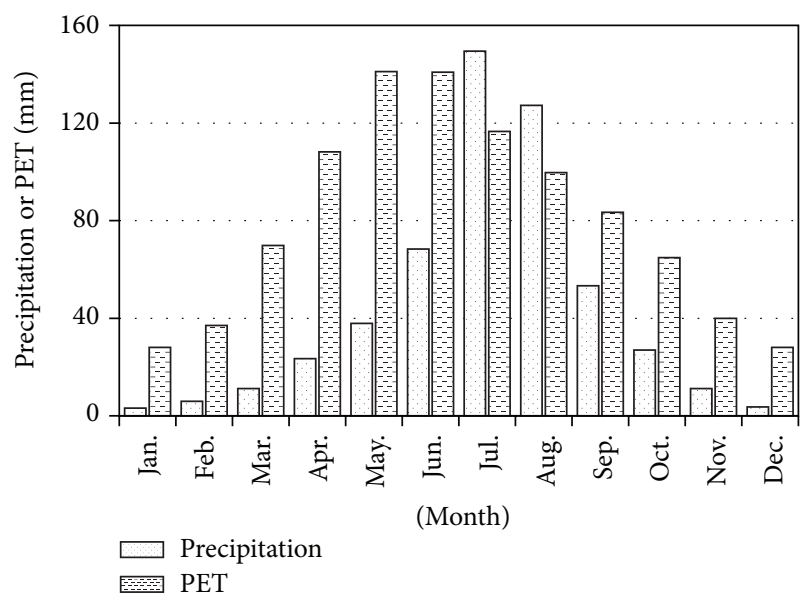

FIgURE 2: Average monthly areal precipitation and PET in Haihe River basin during 1961-2010.

\section{Data and Methods}

3.1. Data Sources. The daily meteorological data (consisting of precipitation; minimum, maximum, and average temperature; average wind speed; sunshine hours; relative humidity) of 52 stations (Figure 1) from January 1961 to December 2010 were originally acquired from China Meteorological Data Sharing Service System (http://cdc.nmic.cn/home.do). Based on the daily meteorological data, the daily potential 
evapotranspiration (PET) was calculated through PenmanMonteith equation (FAO.56 P-M equation), which is an efficient physical-based method and has been used to estimate the potential evapotranspiration in Haihe River basin [17]. Accordingly the monthly and annual precipitation and PET were accumulated from the daily precipitation and PET at station scale. Moreover, monthly precipitation and PET of 52 stations were interpolated into $1 \times 1 \mathrm{~km}$ grids over the Haihe River basin by the Kriging interpolation. Finally, the monthly areal precipitation and PET were obtained based on the average monthly precipitation and PET of all grids in Haihe River basin from January 1961 to December 2010, and annual areal precipitation and PET were accumulated from the monthly areal precipitation and PET. Consequently, annual areal AET was calculated via Budyko equation based on the annual areal precipitation and PET; monthly AET was obtained according to the monthly areal precipitation and evapotranspiration coefficient.

3.2. Kolmogorov-Smirnov Test. The statistic $D_{n}(\mathrm{~K}-\mathrm{S} D)$ value given by Kolmogorov-Smirnov (K-S) test $[18,19]$ is a simple and efficient method to test whether a variable series comes from some completely specified distribution, which is applied to identify a suitable distribution for the water budget. It is a nonparametric test well-known as follows:

$$
D_{n}=\max \left|F\left(x_{i}\right)-S\left(x_{i}\right)\right| \quad i=1,2, \ldots, n,
$$

where $x_{i}$ is the variable series to be test; $S\left(x_{i}\right)$ is the sample empirical cumulative distribution function; and $F\left(x_{i}\right)$ is the theoretical cumulative distribution function estimated from the samples.

3.3. Statistic Indices. Pearson correlation coefficient (PCC; see (2)) and Root Mean Square Error (RMSE; see (3)) were employed to analyze the relation and difference between multiscalar drought indices and sc-PDSI at different time scales and expressed as follows:

$$
\begin{aligned}
\operatorname{PCC} & =\frac{\operatorname{cov}(x, y)}{\sqrt{\operatorname{Var}(x)} \sqrt{\operatorname{Var}(y)}}, \\
\operatorname{RMSE} & =\sqrt{\frac{\sum_{i=1}^{n}(x-y)^{2}}{n}},
\end{aligned}
$$

where $x$ presents the variable series of multiscalar drought indices, $y$ presents the series of sc-PDSI, and $n$ is the length of the data series $(n=600)$.

3.4. Mann-Kendall Trend Test. As a nonparametric test method recommended by the World Meteorological Organization, Mann-Kendall trend test (M-K trend test) $[20,21]$ is widely used in meteorology, hydrology, and climatology [22]. The test statistic $U$ is established:

$$
\begin{aligned}
U & =\frac{\tau}{\sqrt{\operatorname{Var}(\tau)}}, \\
\tau & =\frac{4 p}{\sqrt{n(n-1)}}-1, \\
p & =\sum_{i=1}^{k} \sum_{j}^{i-1} a_{i j}, \quad(k=2,3, \ldots, n), \\
a_{i j} & =\left\{\begin{array}{ll}
1 \quad x_{i}>x_{j} \\
0 \quad x_{i} \leq x_{j}
\end{array} \quad(1 \leq j \leq i),\right. \\
\operatorname{Var}(\tau) & =\frac{2(2 n+5)}{9 n(n-1)}, \\
\beta & =\operatorname{Median}\left(\frac{x_{j}-x_{i}}{j-i}\right), \quad \forall i<j,
\end{aligned}
$$

where $n$ is the length of the data series $(n=600), p$ is the allelomorph of the series, $\beta$ is the magnitude of the trend, and $U$ is the test statistic value of the trend $\beta$. The positive $U$ indicates that the series has an increasing trend; otherwise, the series has a decreasing trend. Moreover, if $|U|>U \alpha=$ 1.96 while the significance level is $\alpha=0.05$, then the series has passed the significance test with a significant trend.

\section{Construction of SWBI}

4.1. Calculation of Evapotranspiration. The PET is an important variable in hydrological cycle. The most suitable calculation method for daily PET in Haihe River basin is the P-M equation [23], which consists of multiple climatic factors such as temperature and average wind speed; sunshine hours; and relative humidity and is a comprehensive and standardized equation for estimating reference potential evapotranspiration $\left(\mathrm{PET}_{0}\right)$ calculated as follows [24]:

$$
\begin{array}{rl}
\mathrm{PET}_{0} & \\
= & \frac{0.408 \Delta\left(R_{n}-G\right)+\gamma(900 /(T+273)) U_{2}\left(e_{a}-e_{d}\right)}{\Delta+\gamma\left(1+0.34 U_{2}\right)}, \\
e_{s} & 0.3054 \\
& \times\left[\exp \left(\frac{17.27 T_{\min }}{T_{\min }+237.3}\right)+\exp \left(\frac{17.27 T_{\max }}{T_{\max }+237.3}\right)\right] \\
e_{a}= & e_{s} \frac{\mathrm{RH}}{100}, \\
\Delta= & \frac{4098 \times[0.6108 \times \exp (17.27 T /(T+237.3))]}{(T+237.3)^{2}},
\end{array}
$$

where $\mathrm{PET}_{0}$ is the reference potential evapotranspiration, $\mathrm{mm} / \mathrm{d}$. Assuming the vegetation height as $0.12 \mathrm{~m}$, the canopy 

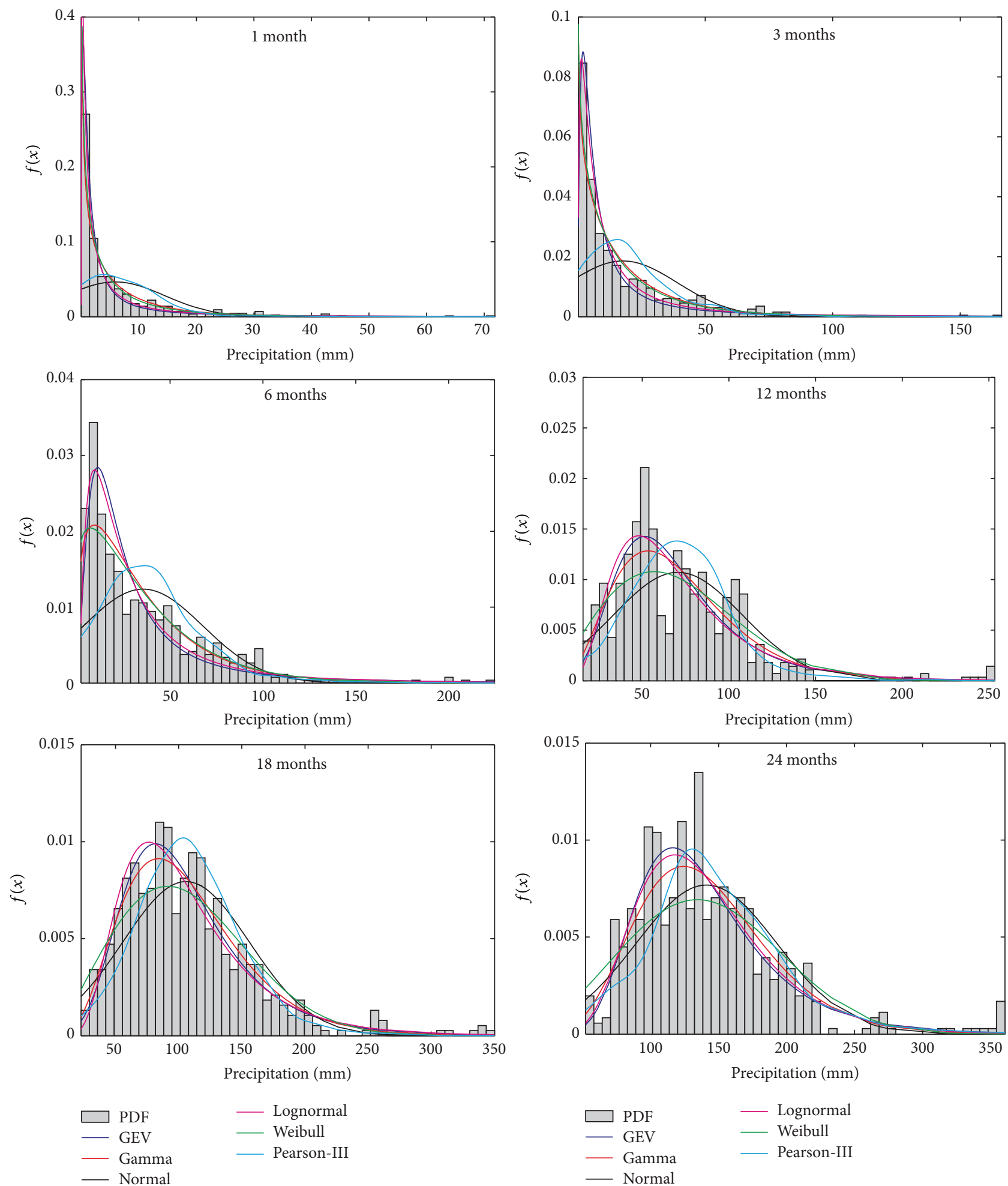

FIGURE 3: Empirical and modeled $f(x)$ values using the Generalized Extreme Value (GEV), Gamma, Normal, Lognormal, Weibull, and Pearson-III distributions of the water budget series at different time scales.

resistance as $70 \mathrm{~s} / \mathrm{m}$, the ground surface reflectivity as 0.23 when calculating $\mathrm{PET}_{0}, \mathrm{RH}$ is daily relative humidity, \%; $R_{n}$ is the net radiation at the crop surface and calculated based on the sunshine hours and latitude of location (http://www.fao.org/docrep/X0490E/x0490e00.htm\#Contents),
$\mathrm{MJ} / \mathrm{m}^{2} \cdot \mathrm{d} ; G$ is the soil heat flux density $(G \approx 0$ for day and ten-day periods), $\mathrm{MJ} / \mathrm{m}^{2} \cdot \mathrm{d} ; T, T_{\min }$, and $T_{\max }$ are daily mean, minimum, and maximum air temperature at $2 \mathrm{~m}$ height, ${ }^{\circ} \mathrm{C}$; $U_{2}$ is wind speed at $2 \mathrm{~m}$ height, $\mathrm{m} / \mathrm{s} ; e_{d}$ is the saturation vapor pressure, $\mathrm{kPa} ; e_{a}$ is the actual measured vapor pressure, $\mathrm{kPa}$; 
$\Delta$ is the slope vapor pressure curve that represents the slope of the saturation vapor pressure temperature relationship, $\mathrm{kPa} /{ }^{\circ} \mathrm{C} ; \gamma$ is the psychrometric constant $(\gamma=0.039$ in this study), $\mathrm{kPa} /{ }^{\circ} \mathrm{C}$. Detailed information about $\mathrm{P}-\mathrm{M}$ equation can been seen in FAO Irrigation and Drainage Paper 56.

Although the AET is a complicated processes seriously impacted by the precipitation, PET, and underlying surface system, the available energy and water are the primary factors determining the evapotranspiration $[25,26]$. Hence, Budyko (1974) developed an empirical equation to estimate annual areal AET. It is widely used to study basin-scale water and energy balances [27] and expressed as

$$
\begin{aligned}
& \mathrm{AET}^{a}=\left[P^{a} \times\left(1-\exp \left(-\frac{\mathrm{PET}^{a}}{P^{a}}\right)\right) \times \mathrm{PET}^{a}\right. \\
& \left.\times \tanh \left(\frac{P^{a}}{\mathrm{PET}^{a}}\right)\right]^{0.5},
\end{aligned}
$$

where $\mathrm{AET}^{a}, P^{a}$, and $\mathrm{PET}^{a}$ are annual areal actual evapotranspiration, precipitation, and potential evapotranspiration of Haihe River basin, respectively; a ranges from 1960 to 2010 in this study.

However, monthly areal AET is more complicated to calculate compared with annual areal AET since the monthly water budget is more sensitive to impact factors such as hydrometeorology, underlying surface system, and antecedent soil moisture. Under a rough assumption that monthly evapotranspiration coefficient $\left(\mathrm{ETC}_{i}^{a}=\mathrm{AET}_{i}^{a} / P_{i}^{a}\right)$ is approximately equal to annual evapotranspiration coefficient $\left(\mathrm{ETC}^{a}=\mathrm{AET}^{a} / P^{a}\right)$, monthly areal AET can be obtained as follows:

$$
\mathrm{AET}_{i}^{a}=P_{i}^{a} \times \frac{\mathrm{AET}^{a}}{P^{a}}=\mathrm{AET}^{a} \times \frac{P_{i}^{a}}{P^{a}}
$$

where $\mathrm{AET}_{i}^{a}$ and $P_{i}^{a}$ are the areal actual evapotranspiration and precipitation of Haihe River basin in $i$ th month at year $a$ accordingly.

4.2. Calculation of SWBI. According to the water budget, monthly water budget can be expressed as

$$
W_{i}^{a}=P_{i}^{a}-\mathrm{AET}_{i}^{a}=R_{i}^{a}+\Delta S_{i}^{a},
$$

where $P_{i}^{a}, \operatorname{AET}_{i}^{a}, R_{i}^{a}$, and $\Delta S_{i}^{a}$ are the areal precipitation, actual evapotranspiration, runoff, and variation of soil moisture of the $i$ th month in the year $a$, respectively. $W_{i}^{a}$ is the water budget of Haihe River basin, which consists of variation of soil moisture and runoff. As a result, water budget is a comprehensive drought index, which can describe hydrological drought but also depict the drought/wet condition of soil moisture.

The monthly water budget [28] is a signal of drought/wet for the month $i$, and the accumulated water budget $\left(W_{i, k}\right)$ is calculated as a multiple time scales drought/wet measure:

$$
W_{i, k}=\sum_{i=i-k+1}^{i=i} W_{i}
$$

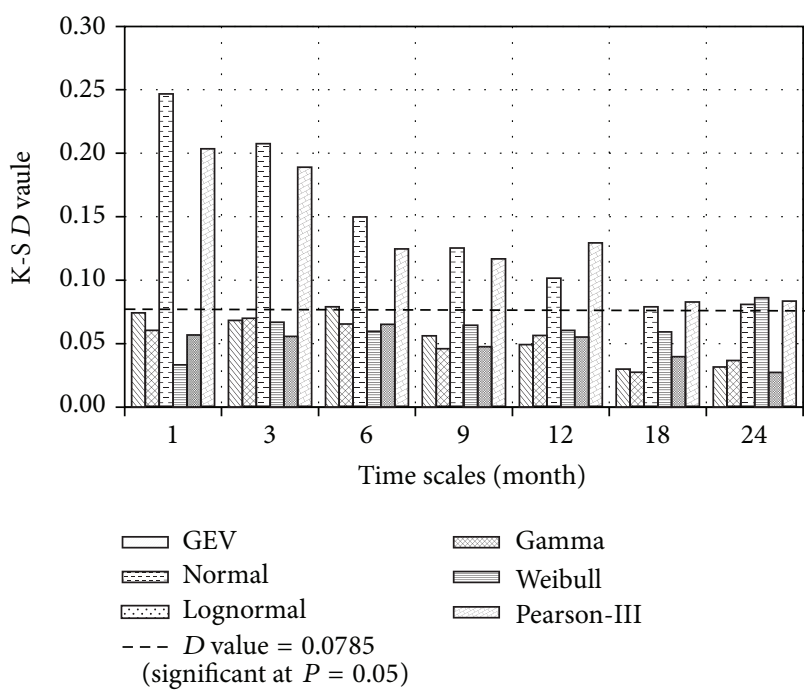

FIGURE 4: K-S $D$ value of water budget by different distribution function.

where $W_{i, k}$ is the accumulated water budget of $i$ th month at time scale $k$.

Subsequently, six common distributions (Generalized Extreme Value (GEV), Gamma, Normal, Lognormal, Weibull, and Pearson-III distribution) were applied to model the water budget series $W_{i, k}$ at different time scales, and the empirical and modeled $f(x)$ were shown in Figure 3. Furthermore, the Kolmogorov-Smirnov test was used to choose the most suitable probability distribution function for water budget series. The result displays that only K-S $D$ value of Gamma and Lognormal distribution achieves significance $(P=0.05)$ at all time scales (Figure 4$)$.

Based on the Budyko curve, the annual AET is less than precipitation. Therefore, $W_{i}$ derived from (8) and (9) is a positive and proportional to precipitation. Then, the Gamma and Lognormal distribution were applied to construct SWBI, separately. When Gamma distribution was selected to match the distribution of water budget series $W_{i, k}, F(x)$ values of $W_{i, k}$ series can be obtained from same procedure in SPEI and are formulated by (10) to (15). One has

$$
\begin{aligned}
& g(x)=\frac{1}{\beta^{\alpha} \Gamma(\alpha)} x^{\alpha-1} e^{-x / \beta}, \quad x>0 \\
& \Gamma(x)=\int_{0}^{\infty} x^{\alpha-1} e^{-x} d x,
\end{aligned}
$$

where $x$ is $W_{i, k}$ series at different time scales (the time scale of $1,3,6,9,12,18$, and 24 months was taken into consideration in this study); $\Gamma(x)$ is the Gamma function; $\alpha$ and $\beta$ are the shape and scale parameters, respectively, which can be calculated as follows:

$$
\begin{aligned}
& A=\lg \bar{x}-\frac{1}{n} \sum_{i=1}^{n} \lg x_{i}, \\
& \alpha=\frac{1+\sqrt{1+4 A / 3}}{4 A}, \\
& \beta=\frac{\bar{x}}{\alpha},
\end{aligned}
$$


where $n$ is the length of the time series. Accordingly, $W_{i, k}$ series obeys the accumulative distribution $G(x)$ :

$$
G(x)=\frac{1}{\beta^{\alpha} \Gamma(\alpha)} \int_{0}^{x} t^{\alpha-1} e^{-t / \beta} d t, \text { for } x>0 .
$$

However, $G(x)$ does not take the extreme scenario $(x=0)$ into account and then $G(x)$ is modified as $F(x)$ :

$$
F(x)=q+(1-q) G(x) .
$$

$$
\text { gam-SWBI }= \begin{cases}t-\frac{c_{0}+c_{1} t+c_{2} t^{2}}{1+d_{1} t+d_{2} t^{2}+d_{3} t^{3}}, & t=\sqrt{-2 \ln (1-F(x))}, \quad 0.5<F(x)<1.0 \\ \frac{c_{0}+c_{1} t+c_{2} t^{2}}{1+d_{1} t+d_{2} t^{2}+d_{3} t^{3}}-t, & t=\sqrt{-2 \ln (F(x))}, \quad 0<F(x) \leq 0.5,\end{cases}
$$

where $q$ is the probability of exceeding $x$ (14); the constants $c_{0}=2.51557, c_{1}=0.802853, c_{2}=0.010328, d_{1}=1.432788, d_{2}=$ 0.189269 , and $d_{2}=0.001308$.

In contrast, $F(x)$ values of $W_{i, k}$ series can be calculated through (16) to (19), while the Lognormal distribution is selected to fit the distribution of water budget series $W_{i, k}$ (i.e., $\operatorname{logn}-\mathrm{SWBI}$ ), and the value of logn-SWBI also agrees with the classification of SWBI (Table 1):

$$
\begin{aligned}
f(x) & =\frac{1}{\sigma \sqrt{2 \pi}} \exp \left[-\frac{(\ln x-\mu)}{2 \sigma^{2}}\right], \quad x>0 \\
\mu & =\frac{\sum_{i=1}^{n} \ln x_{i}}{n}, \\
\sigma & =\sqrt{\frac{\sum_{i=1}^{n}\left(\ln x_{i}-\mu\right)^{2}}{n}}, \\
\operatorname{logn}-\mathrm{SWBI} & =\int_{0}^{x} t f(t) \mathrm{d} t
\end{aligned}
$$

where $x$ is $W_{i, k}$ series at different time scales.

Finally, the gam-SWBI and logn-SWBI were calculated separately, and the PCCs between gam-SWBI/logn-SWBI and sc-PDSI at different time scales are shown in Figure 5. It indicates that the PCCs between gam-SWBI and sc-PDSI are higher than that between logn-SWBI and sc-PDSI, which implies that gam-SWBI is better than logn-SWBI to describe drought condition and Gamma distribution is more suitable distribution for the water budget at different time scales. Consequatly, gam-SWBI is the defaulted SWBI formulated by (10) to (15) in this paper.

\section{Results and Discussion}

5.1. Validation in Drought Evolution. The multiscalar drought indices (SPI, RDI, SPEI, and SWBI) at different time scales were applied into comparison with the sc-PDSI in Haihe River basin from 1961 to 2010 (Figure 6), since the sc-PDSI is a reference index for measuring meteorological drought based on simple water balance model [10], in which the PET was
Then $F(x)$ needs to be transformed into standard Normal distribution (see (15)), and the gam-SWBI can be calculated following the classical approximation [28]; the drought classification of SWBI and the corresponding occurrence probabilities of each severity level are listed in Table 1 according to the classification of SPEI [1]: calculated through the P-M equation instead of Thornthwaite method. The result displays that both multiscalar drought indices and sc-PDSI show that there are three typical interannual drought episodes which occurred in 1980-1985, 19992003, and 2005-2008, which is consistent with the result by the previous research in Haihe River basin [2]. In addition, PCCs between multiscalar drought indices and sc-PDSI are shown in Figure 7(a). It demonstrates that the multiscalar drought indices correlate well with the sc-PDSI on the time scale around 12 months, which is consistent with the research by VICENTE-SERRANO (2010). SWBI performs better than the other multiscalar drought indices with higher PCCs at the time scale within 12 months. Figure 7(b) illustrates the RMSE between multiscalar drought indices and sc-PDSI at different time scales, and the results present that the RMSE of SWBI is the smallest among the RMSEs of multiscalar drought indices, which implies that SWBI outperforms other multiscalar drought indices in Haihe River basin.

5.2. Validation in Drought Trend. M-K trend test was used to examine trends of drought indices in Haihe River basin from 1961 to 2010 at different time scales (Figure 8). It displays that trends of all the multiscalar drought indices were decreasing (negative). Although the increase in temperature makes an increase of PET, the increase in vapor pressure driven by the decrease in wind and solar radiation has offset the effect of temperature [17]. Therefore, the possible reason is that the decreasing precipitation contributes to the decreasing trend of drought in Haihe River basin [29]. The trends of drought decrease along with the increasing time scale due to the accumulative effect of water budget series. Meanwhile, the decreasing trend of sc-PDSI is -0.004 and obviously stronger than the decreasing trends of multiscalar drought indices. The reason is that the amplitude of sc-PDSI is nearly twice as much as multiscalar drought indices. Furthermore, the decreasing trends of SPI, RDI, and SPEI are insignificant at time scale of 1 and 3 months and inconsistent with significant decreasing trends of SPI, RDI, and SPEI at time scales more than 3 months. Thus, it implies that there is an uncertain timescale effect on the multiscalar drought assessment for 
TABLE 1: SWBI classification.

\begin{tabular}{lc}
\hline SWBI value & SWBI category \\
\hline SWBI $>2.0$ & Extreme wet conditions \\
$1.5<$ SWBI $\leqslant 2.0$ & Severe wet conditions \\
$1.0<$ SWBI $\leqslant 1.5$ & Moderate wet conditions \\
$0.5<\mathrm{SWBI} \leqslant 1.0$ & Mild wet conditions \\
$-0.49<\mathrm{SWBI} \leqslant 0.5$ & Near normal \\
$-1.0<\mathrm{SWBI} \leqslant-0.5$ & Mild drought \\
$-1.5<\mathrm{SWBI} \leqslant-1.0$ & Moderate drought \\
$-2.0 \leqslant \mathrm{SWBI} \leqslant-1.5$ & Severe drought \\
SWBI $<-2.0$ & Extreme drought \\
\hline
\end{tabular}

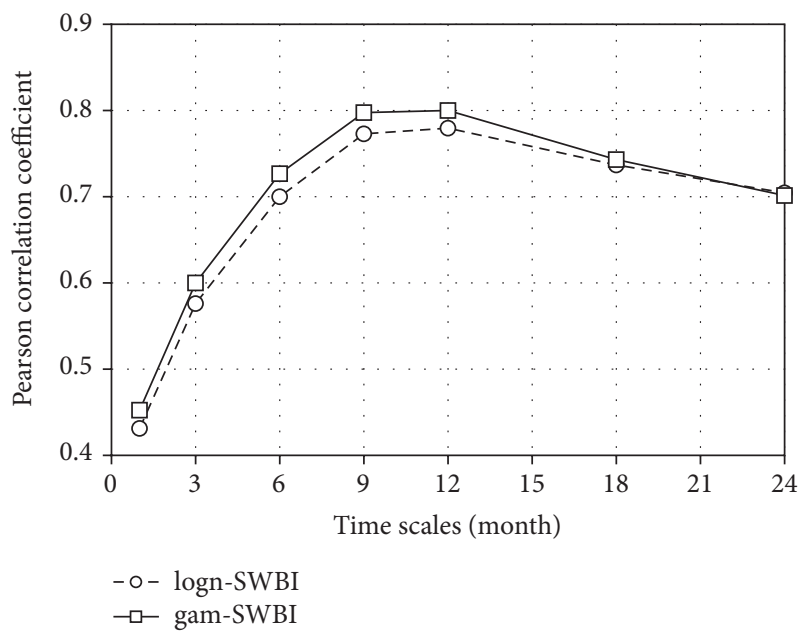

Figure 5: Pearson correlation coefficients between logn-SWBI/ gam-SWBI and sc-PDSI.

SPI, RDI, and SPEI. In contrast, the trends of SWBI are consistent and more stable at different time scales. Therefore, it reveals that SWBI is more suitable to describe the drought trend in Haihe River basin, especially at time scales less than 3 months.

Figure 9 shows the drought episodes of different drought classifications in Haihe River basin during 1961-2010 at time scale of 12 months, which is the most consistent time scale for the relation between sc-PDSI and multiscalar drought indices. The result demonstrates that the number of drought months identified by sc-PDSI is much larger than that of multiscalar drought indices in the mild and moderate drought and smaller than that of multiscalar drought indices in severe and extreme drought. The possible reason is that scPDSI was derived from water balance model, during which the soil moisture regulating function plays an important role in controlling extreme climate events. Moreover, the number of drought months identified by SWBI is more close to that of sc-PDSI in different drought classification.

\subsection{Discussions on Rationality of Actual Evapotranspiration.} The relation between annual areal AET/precipitation and annual PET/precipitation is shown in Figure 10. It indicates that the areal AET obtained from the empirical equation
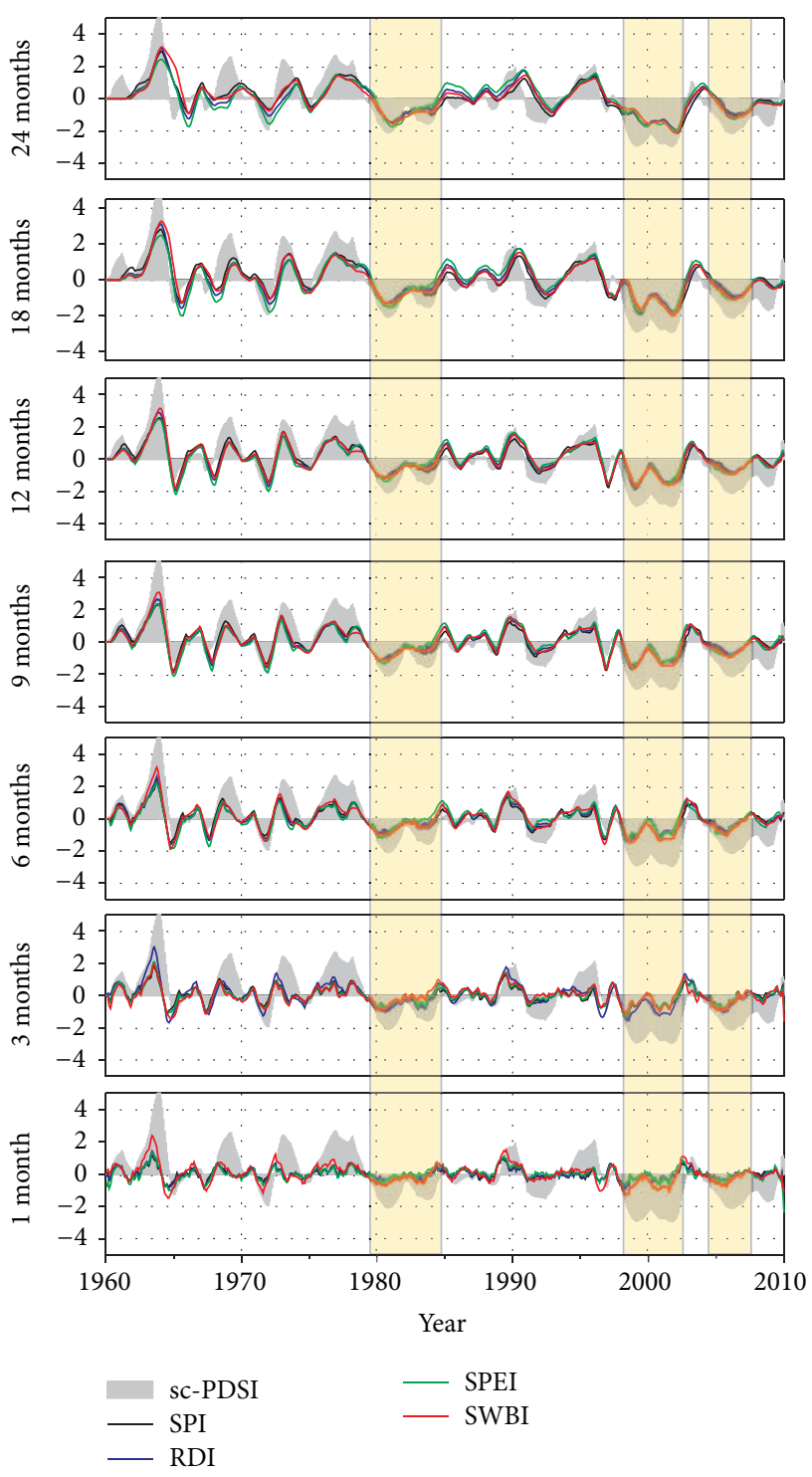

FIgURE 6: Comparisons of the drought indices at multiple time scales in Haihe River basin (the drought indices were smoothed by moving average filter with the span of 12 months, and three serious drought periods are marked by yellow shadows.).

(see (6)) follows the Budyko curve in Haihe River basin. Annual evapotranspiration coefficient $\left(\mathrm{ETC}^{a}=\right.$ annual actual evapotranspiration/precipitation) is stable and has a slightly decreasing trend along with the increasing annual precipitation (Figure 11). However, monthly evapotranspiration coefficient $\left(\mathrm{ETC}_{i}^{a}\right)$ is more variable since the seasonal climate variation. Thus, monthly AET is complicated and sensitive to the influence of hydrometeorology and underlying surface system and cannot be accurately estimated without the hydrological process simulation/observation. Although monthly AET obtained from the assumption that monthly $\mathrm{ETC}_{i}^{a}$ is equal to annual $\mathrm{ETC}^{a}$ is rough approximations, the interannual difference of annual ETC $^{a}$ and innerannual distribution of monthly precipitation will result in an approximate estimation of monthly AET via (7). Then, the relations 


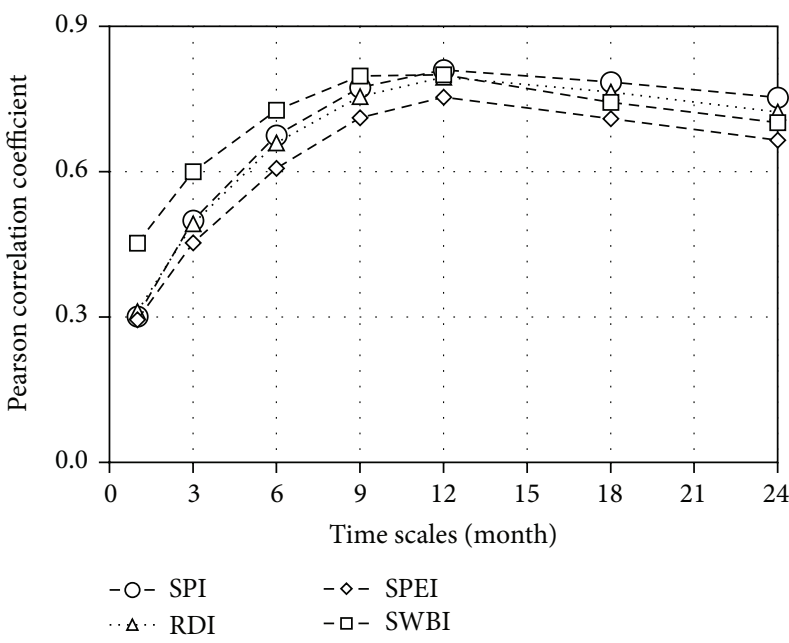

(a)

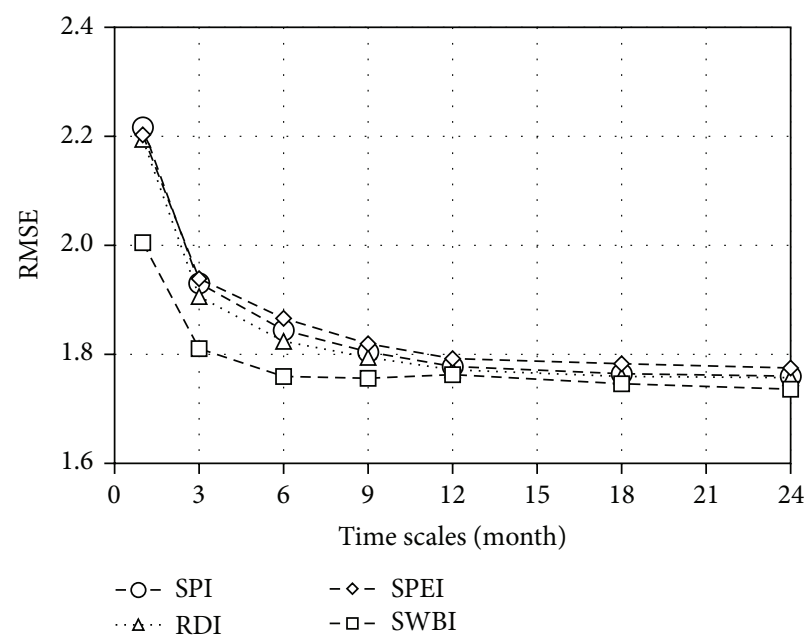

(b)

FIGURE 7: Pearson correlation coefficients and RMSE between multiscalar drought indices and sc-PDSI at different time scale.

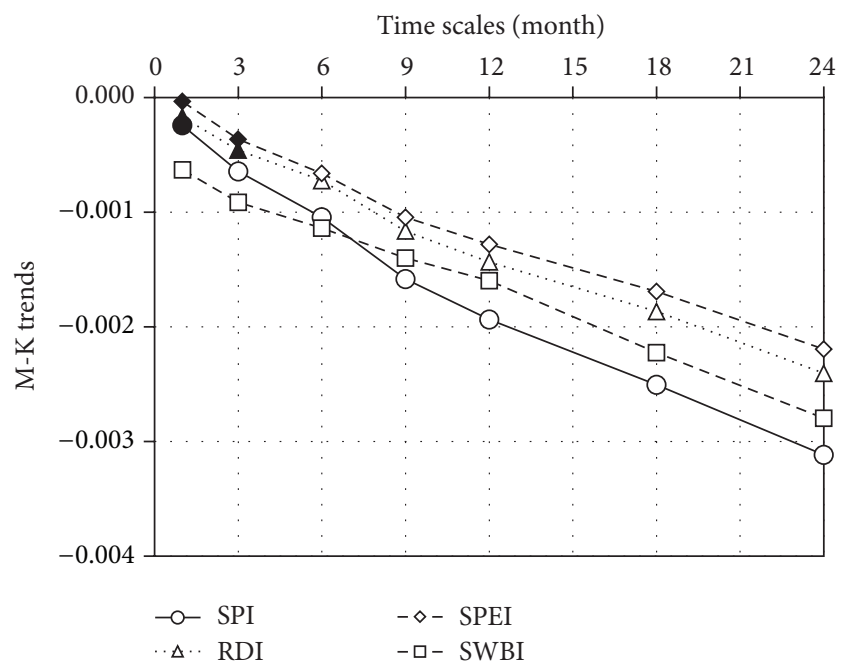

FIGURE 8: Mann-Kendell trends of drought indices: solid dots represent the decreasing trends which are insignificant, while open dots indicate the decreasing trends which are significant at $P=0.05$.

between AET and precipitation at monthly and annual scales are illustrated in Figure 12. The result points out that there is an obvious linear relation between AET and precipitation, and the integrated monthly $\operatorname{ETC}_{i}^{a}(0.8550)$ obtained from different annual $\mathrm{ETC}^{a}$ and monthly precipitation is approximately equal to integrated annual $\mathrm{ETC}^{a}(0.8558)$ from 1961 to 2010 in Haihe River basin, which implies that the calculation of annual and monthly AET is feasible in the paper.

\section{Summary and Conclusions}

In this study, SWBI was constructed based on the actual water budget, which was derived from the difference between areal precipitation and AET and followed the Gamma distribution.

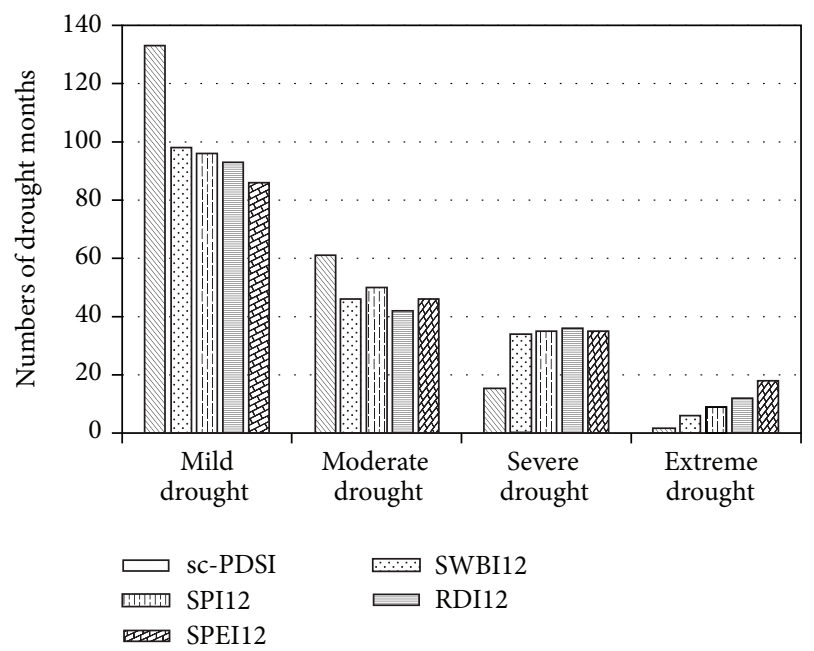

Figure 9: Drought episodes of different drought classifications identified by drought indices at time scale of 12 months.

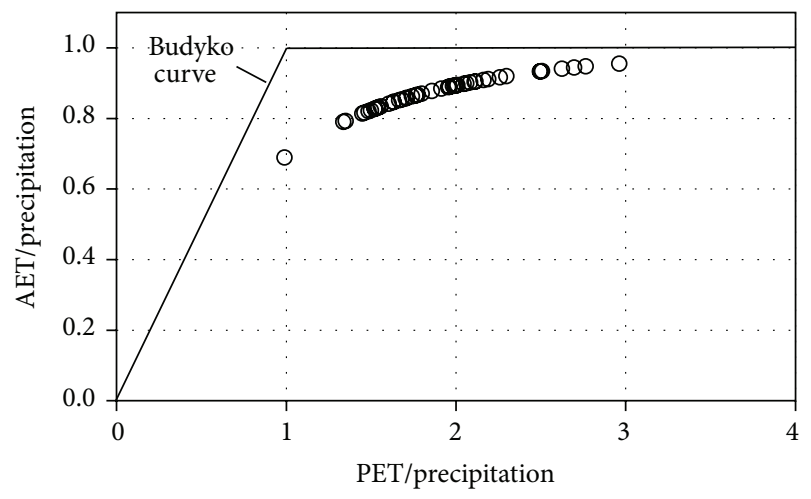

FIGURE 10: Relation between annual AET/precipitation and annual $\mathrm{PET} /$ precipitation. 


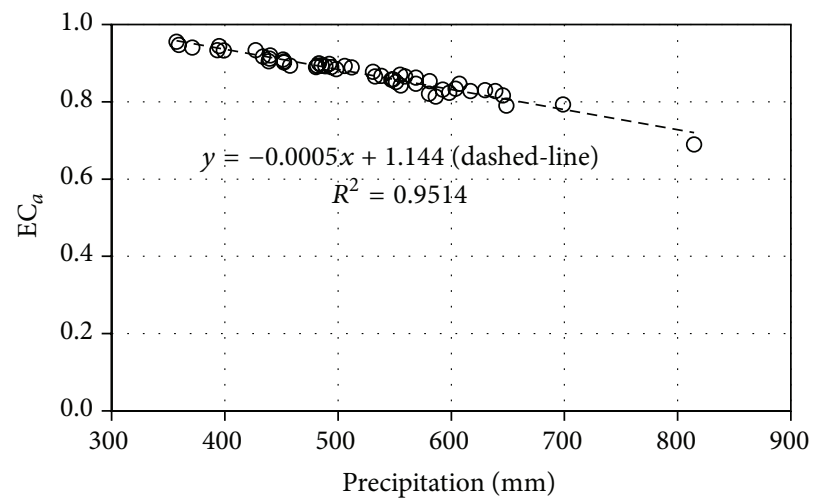

FIGURE 11: Relation between annual evapotranspiration coefficient and precipitation.

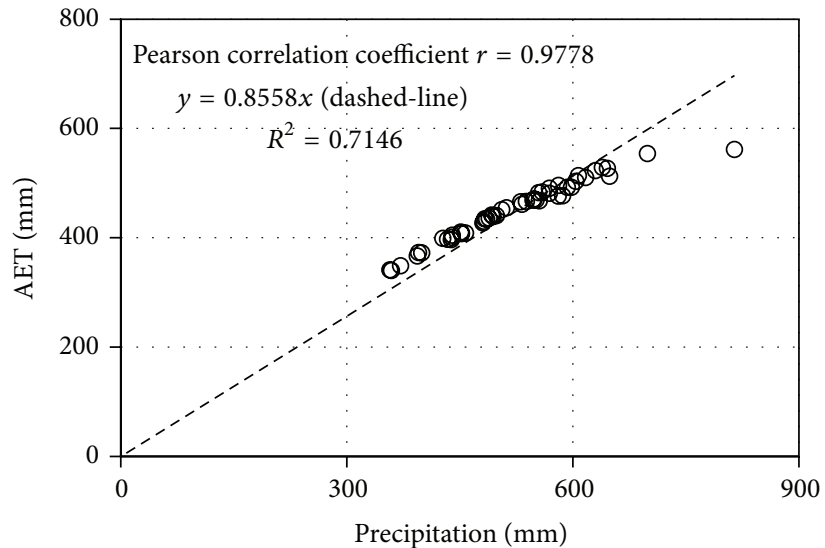

(a)

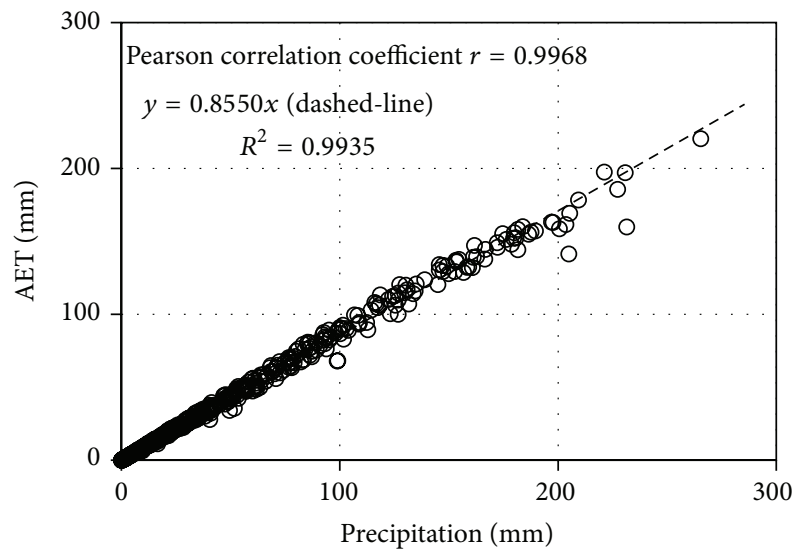

(b)

FIGURE 12: Annual and monthly relations between actual evapotranspiration and precipitation: (a) annual relation; (b) monthly relation.

Then sc-PDSI was taken as the reference drought index to compare with multiscalar drought indices (SPI, RDI, SPEI, and SWBI) in Haihe River basin from 1961 to 2010; the result displays the following:

(1) Multiscalar drought indices correlate highly with scPDSI at the time scale around 12 months, and SWBI correlates better with sc-PDSI than other multiscalar drought indices with higher PCCs at the time scale less than 12 months. Moreover, the RMSE of SWBI was less than that of other multiscalar drought indices.

(2) Three typical interannual drought episodes occurred in 1980-1985, 1999-2003, and 2005-2008 were identified by all of the drought indices, and there is an obviously decreasing trend of drought indices, possibly due to the decreasing precipitation. Moreover, the decreasing trend of SWBI is significant at all the time scales; meanwhile decreasing trend of other multiscalar drought indices is insignificant at time scales less than 3 months. Additionally, the numbers of drought months derived from SWBI in different drought classification were more close to the sc-PDSI than other multiscalar drought indices at time scale of 12 months.

According to the aforementioned results, it can be concluded that SWBI is more suitable for drought estimation in Haihe River basin. On the one hand, SWBI derived from water budget is more flexible than sc-PDSI due to the multiscalar characters and convenient calculation. On the other hand, SWBI takes more meteorological factors into consideration than SPI, and the actual water budget in SWBI calculated by the difference between AET and precipitation agrees better with natural water budget than that in SPEI. Nevertheless, the calculation methods of monthly and annual AET are empirical and generalized in SWBI. Therefore, it will be meaningful to improve the accuracy of AET, particularly the monthly AET, for SWBI in the future researches.

\section{Competing Interests}

The authors declare that there are no competing interests regarding the publication of this paper. 


\section{Acknowledgments}

This work was supported by the General Program of the National Natural Science Foundation of China (51279207 and 51409266); the National Science and Technology Support Program Project (2013BAC10B01); the International Science \& Technology Cooperation Program of China (2013DFG70990).

\section{References}

[1] S. M. Vicente-Serrano, S. Beguería, and J. I. López-Moreno, "A multiscalar drought index sensitive to global warming: the standardized precipitation evapotranspiration index," Journal of Climate, vol. 23, no. 7, pp. 1696-1718, 2010.

[2] Y. Qin, D. Yang, H. Lei, K. Xu, and X. Xu, “Comparative analysis of drought based on precipitation and soil moisture indices in Haihe basin of North China during the period of 1960-2010," Journal of Hydrology, vol. 526, pp. 55-67, 2015.

[3] M. M. Sohrabi, J. H. Ryu, J. Abatzoglou, and J. Tracy, "Development of soil moisture drought index to characterize droughts," Journal of Hydrologic Engineering, vol. 20, no. 11, Article ID 04015025, 2015.

[4] A. Dai, "Drought under global warming: a review," Wiley Interdisciplinary Reviews: Climate Change, vol. 2, no. 1, pp. 4565, 2011.

[5] A. K. Mishra and V. P. Singh, "A review of drought concepts," Journal of Hydrology, vol. 391, no. 1-2, pp. 202-216, 2010.

[6] M. Gocic and S. Trajkovic, "Water surplus variability index as an indicator of drought," Journal of Hydrologic Engineering, vol. 20, no. 2, Article ID 04014038, 7 pages, 2014.

[7] W. C. Palmer, Meteorological Drought, US Department of Commerce, Washington, DC, USA, 1965.

[8] T. B. McKee, N. J. Doesken, and J. Kleist, "The relationship of drought frequency and duration to time scales," in Proceedings of the 8th Conference on Applied Climatology, pp. 179-183, Boston, Mass, USA, 1993.

[9] A. A. Paulo, R. D. Rosa, and L. S. Pereira, "Climate trends and behaviour of drought indices based on precipitation and evapotranspiration in Portugal," Natural Hazards and Earth System Science, vol. 12, no. 5, pp. 1481-1491, 2012.

[10] N. Wells, S. Goddard, and M. J. Hayes, "A self-calibrating palmer drought severity index," Journal of Climate, vol. 17, no. 12, pp. 2335-2351, 2004.

[11] G. Tsakiris, D. Pangalou, and H. Vangelis, "Regional drought assessment based on the Reconnaissance Drought Index (RDI)," Water Resources Management, vol. 21, no. 5, pp. 821-833, 2007.

[12] H. Vangelis, M. Spiliotis, and G. Tsakiris, "Drought severity assessment based on bivariate probability analysis," Water Resources Management, vol. 25, no. 1, pp. 357-371, 2011.

[13] S. M. Vicente-Serrano, G. Van der Schrier, S. Beguería, C. Azorin-Molina, and J.-I. Lopez-Moreno, "Contribution of precipitation and reference evapotranspiration to drought indices under different climates," Journal of Hydrology, vol. 526, pp. 4254, 2015.

[14] K. Xu, D. Yang, H. Yang, Z. Li, Y. Qin, and Y. Shen, "Spatiotemporal variation of drought in China during 1961-2012: a climatic perspective," Journal of Hydrology, vol. 526, pp. 253264, 2015.

[15] M. Yang, D. Yan, Y. Yu, and Z. Yang, "SPEI-based spatiotemporal analysis of drought in Haihe River basin from 1961 to 2010,"
Advances in Meteorology, vol. 2016, Article ID 7658015, 10 pages, 2016.

[16] X. Wang, J. Zhang, S. Shamsuddin et al., "Water resources management strategy for adaptation to droughts in China," Mitigation and Adaptation Strategies for Global Change, vol. 17, no. 8, pp. 923-937, 2012.

[17] H. Zheng, X. Liu, C. Liu, X. Dai, and R. Zhu, "Assessing contributions to panevaporation trends in Haihe River Basin, China," Journal of Geophysical Research: Atmospheres, vol. 114, no. 24, Article ID D24105, 2009.

[18] N. Smirnov, "Table for estimating the goodness of fit of empirical distributions," Annals of Mathematical Statistics, vol. 19, no. 2, pp. 279-281, 1948.

[19] F. J. Massey, “The Kolmogorov-Smirnov test for goodness of fit," Journal of the American Statistical Association, vol. 46, no. 253, pp. 68-78, 1951.

[20] H. B. Mann, "Nonparametric tests against trend," Econometrica, vol. 13, no. 3, pp. 245-259, 1945.

[21] M. G. Kendall, Rank Correlation Methods, Charles Griffin, London, UK, 1975.

[22] J. Yin, D. Yan, Z. Yang et al., "Research on historical and future spatial-temporal variability of precipitation in China," Advances in Meteorology, vol. 2016, Article ID 9137201, 14 pages, 2016.

[23] W. Zhao, B. Liu, and Z. Zhang, "Water requirements of maize in the middle Heihe River basin, China," Agricultural Water Management, vol. 97, no. 2, pp. 215-223, 2010.

[24] R. G. Allen, L. S. Pereira, D. Raes, and M. Smith, Crop Evapotranspiration-Guidelines for Computing Crop Water Requirements, FAO Irrigation and Drainage Paper 56, FAO, Rome, Italy, 1998.

[25] M. I. Budyko, "The heat balance of the earth's surface," Soviet Geography, vol. 2, no. 4, pp. 3-13, 1961.

[26] L. Zhang, K. Hickel, W. R. Dawes, F. H. S. Chiew, A. W. Western, and P. R. Briggs, "A rational function approach for estimating mean annual evapotranspiration," Water Resources Research, vol. 40, no. 2, Article ID W02502, 2004.

[27] D. Li, M. Pan, Z. Cong, L. Zhang, and E. Wood, "Vegetation control on water and energy balance within the Budyko framework," Water Resources Research, vol. 49, no. 2, pp. 969-976, 2013.

[28] M. Abramowitz and I. A. Stegun, Handbook of Mathematical Functions: With Formulas, Graphs, and Mathematical Tables (No.55), Courier Corporation, 1964.

[29] J. Chu, J. Xia, C. Xu, L. Li, and Z. Wang, "Spatial and temporal variability of daily precipitation in Haihe River basin, 19582007," Journal of Geographical Sciences, vol. 20, no. 2, pp. 248260, 2010. 

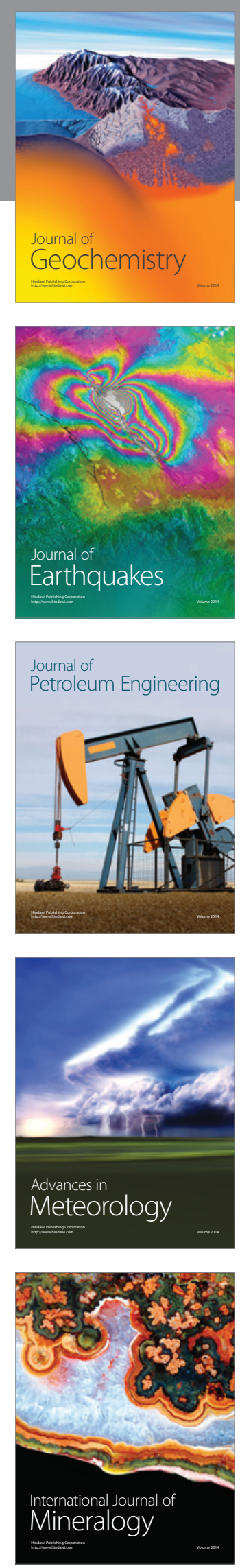
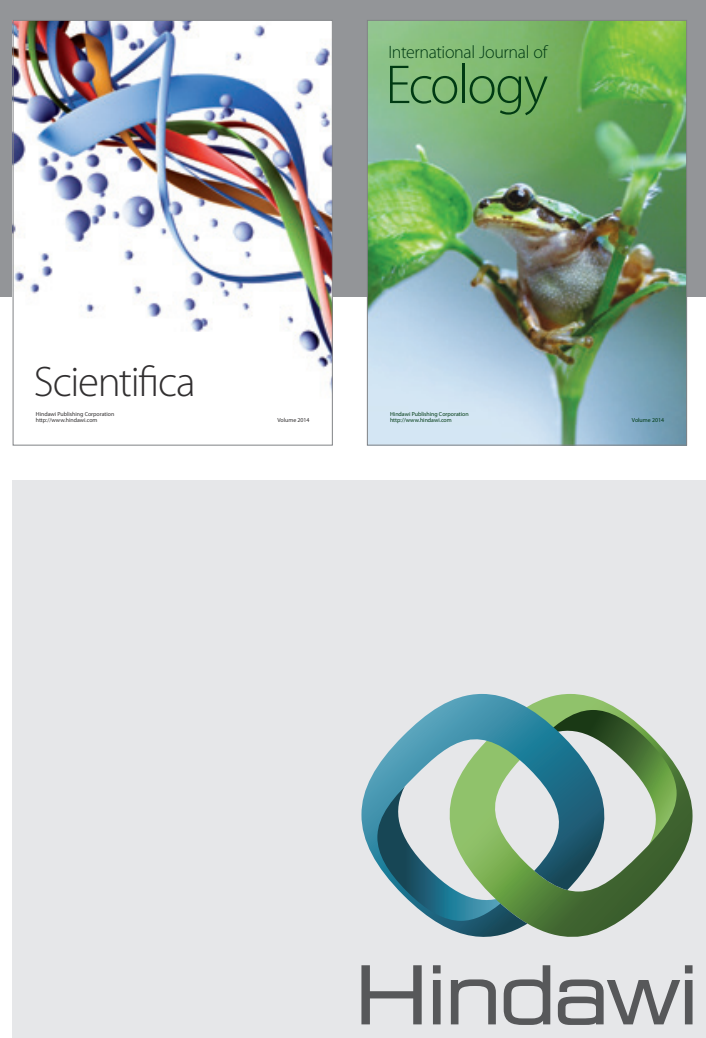

Submit your manuscripts at

http://www.hindawi.com
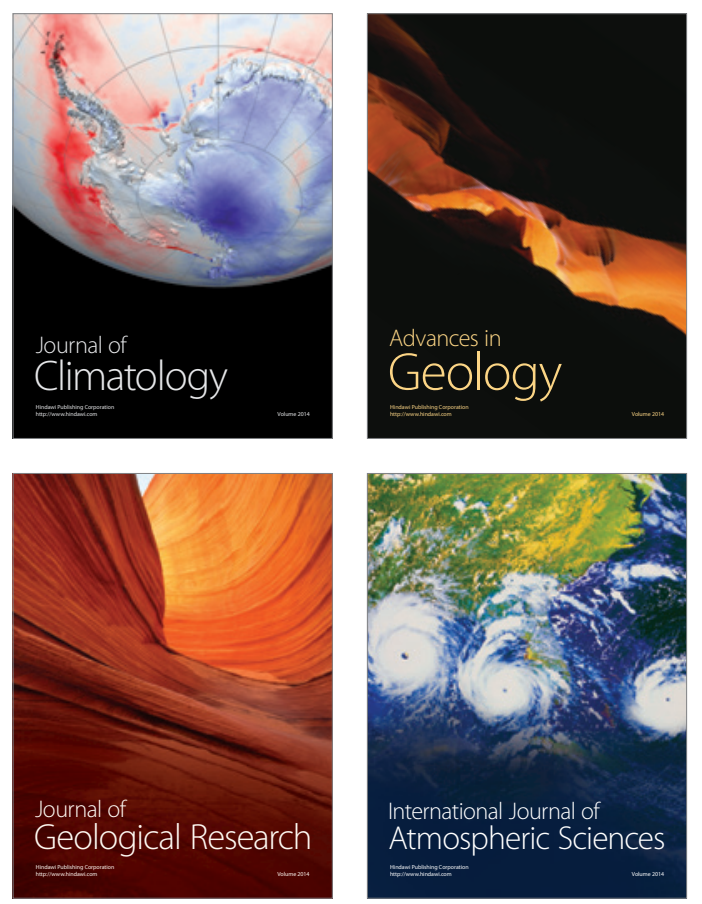

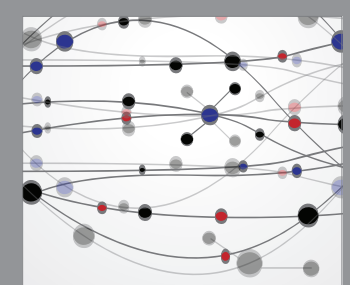

The Scientific

\section{World Journal}
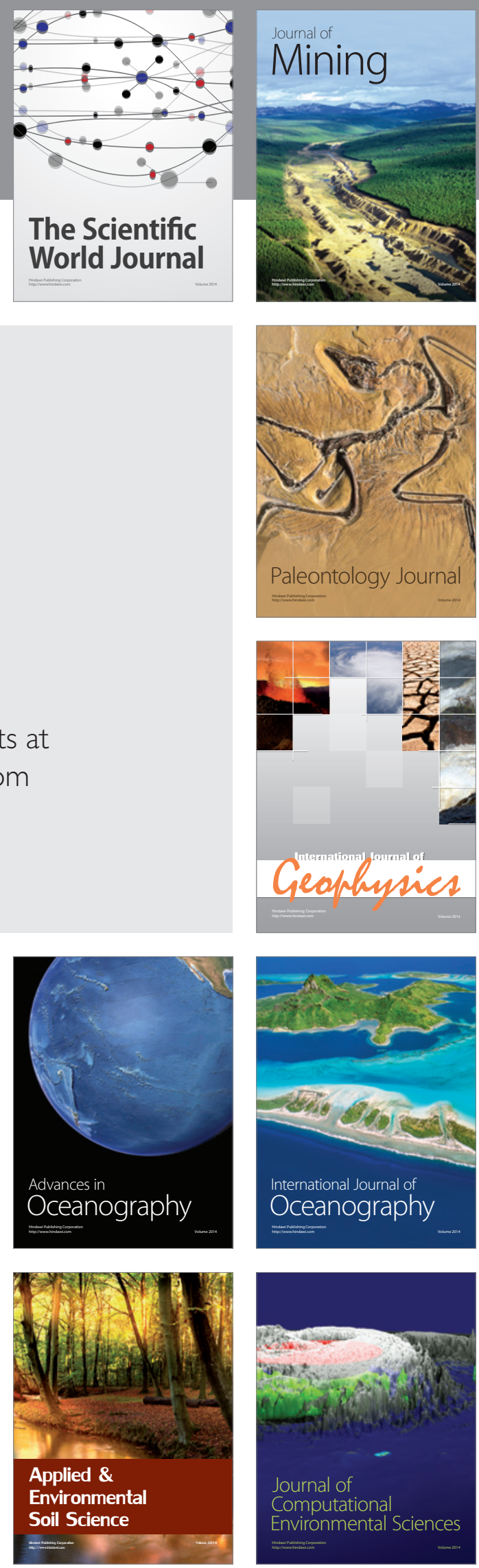